Our dialogue was as follows.

Q. If you were to fire a loaded revolver at, or were to stab a person, what would be the result? $A$. It would kill if me did it with forethought and malice.

$Q$. Do you consider that the commission of such an act would be right or wrong in the sight of God and man? A. Me consider it wrong. Certainly!

Q. What would be done to you if you committed such an offence? $A$. The law says, me should be hanged by the neck until dead.

$Q$. Do you under all circumstances obey the dictates of the spirit within you? $A$. Me do.

This last answer is, of course, an admission that, had he been prompted to commit murder instead of suicide, he would have done so; and I think I may fairly conclude that such a recital of facts requires no comment.

The rule of law relating to the knowledge of right and wrong is also ineffectual ; for, even when the verdict of guilty is passed, we find that the learned judge generally feels bound to acquaint the Home Secretary with the peculiar circumstances of the case, and the result is the same as that which occurred in the case of George Clark; namely, that the prisoner exchanges his cell for the ward of a lunatic asylum.

This rule of law also becomes ineffectual, because it is entirely ignored by the jury; they do not acquit a prisoner because he cannot distinguish between right and wrong, but, as we invariably see, " on the ground of insanity."

As the result of inquiries which I have made in reference to this matter, I feel myself justified in drawing the following conclusions.

1. That, given a number of homicides, all suffering from mental aberration to an equal degree, the verdicts of the juries summoned to try their cases would, if they acted on this rule of law, exhibit a lamentable want of uniformity.

2. That many persors of unsound mind suffer from a form of mental disease, in which, irrespectively of delusion, they are so forcibly prompted to perform that which they know to be evil, that they lose all power of control over their actions.

3. That by far the majority of persons confined as lunatics, who are not absolutely idiotic, imbecile, or demented, know right from wrong.

4. That, if all the lunatics now confined in asylums were to commit murder, at least 90 out of every 100 would, if judged by this rule of law, be found guilty and condemned to death.

\section{CASE OF HERNIA.}

OPERATION: INTESTINE ADHERGNT TO SAC: DEATH : POST MORTEM EXAMINATION.*

By WILLIAM NEWMAN, M.D.Lond.,

Surgeon to the Stamford Infirmary, St. Martin's, Stamford.

J. W., aged 71, was admitted into the Stamford Infirmary on July 10th, 1866, under my care. He was a thin, withered old man, looked anxious, and complained much of pain about and across the abdomen. He stated that he had been ruptured on both sides for some years, and had worn a double truss, but not constantly. The ruptures came down on July 5th; and since that time his bowels had not acted properly. He had, too, been sick on the day of admission and the previous day. Just before I saw him, a little blood-stained mucous stool was passed per anum.

The conditions when I saw him were: Two lax and large inguinal rings, through which movement

- Read before the Shropshire Scientife Branch, Oct. 25th,1860. or conghing sufficed to drive some portion of intis: tine. The so-formed hernim were readily replaced: There was a small nodulated femoral hernia on the left side, which could not entirely be returned. Pressure and manipulation of this did not give pain. A large swelling at the right femoral aperture, of the size of two walnuts, was unaffected by the taxis, was in some measure the seat of pain, unaffected by coughing, and to the touch firm and smooth.

It was agreed, after a consultation of the surgeons, that I should cut down at once on the swelling at the right femoral ring, and make out its real character. The constipation and sickness pointed to strangulation of some part of the intestine; and the symptoms had been present more or less for five days.

The operation was commenced at once. The ordinary incision was made under chloroform; and, after dividing several layers on a director, a thickened and laminated sac was reached. Some serous fluid (blood-stained) escaped when this was opened. A very firm stricture, made by Gimbernat's ligament, was divided upwards and inwards; but the contained intestine, which was dark coloured, much congested, but jet had not lost its polish, could not with any reasonable pressure be returned into the abdomen. The external incision was enlarged, to allow a more close inspection; and then it was found that the knuckle of intestine was firmly adherent, and to some extent, to the sac on the outside and posteriorly; so much so, in the opinion of all present, as to render it unadvisable to make any further attempt at reduction. The operation was of necessity tedious.

July 11 th, 12 A.s. The patient had one grain of opium at 1 A.M., and another grain at 7 A.M. He was fairly comfortable, and did not complain of pain. Pulse 100; tongue rather dry. He had not passed urine; had no sickness since taking the opium. . He was ordered to have milk, beef-tea, and a quarter of a grain of powdered opium erery four hours. A catheter was passed.

7 P.Mr. Pulse 108. He had had a little sleep, and was not in pain.

July 12th. There was little apparent change. The bowels had not acted. Pulse 110 ; tongue dry. The catheter was passed regularly. The abdomen was tympanitic. The wound was dressed with lotion of Condy's fluid $\mathrm{He}$ was ordered four ounces of brandy.

July 13th. He was much the same, not in pain, nor sick. He had slept fairly well. Pulse 103. He was ordered six ounces of brandy.

7 P.Mr. His bowels had acted. An abundant daxk. loose, fæcal motion, with some dysenteric mucus, passed afterwards.

July 14th. He had had a good night; no sickness since the operation. The bowels acted two or three times in the day, and very frequently in the evening. despite the free use of acetate of lead and opium.

July 15 th. He was much worse; was half unconscious. There was no sickness. The bowels had acted very frequently, and the motions now ran away without his knowledge. He was sinking fast.

July 16th. He died at 6 P.M. A few hours before death, frecal matter was found to escape at the. wound.

Post Mortem Examination, July 17th, 2.30 p.M. The abdominal cavity was opened by a central incision from the umbilicus to the pabes, and a transverse one just below the umbilicus, crossing the first one at right angles; and the flaps were thrown back. The external wound was unhealthy in appearance; part of the sac threatening to slough. The intestitio 
ling at the bottom of the wound looked dark, but had not lost its surface-polish. On turning back the abdominal flaps, these conditions were observed. On the left side was a large internal inguinal ring, affording a wide and free entrance into the inguinal canal; but no contents. There was also a large femoral ring. Through this the little finger could be readily passed into a sac prolapsed and adherent to the surrounding parts. The sac was thickened and laminated, and had some shreds of apparently recent lymph stretching across its cavity. It did not contain either omentum or intestine. On the right side was a large internal inguinal ring, much as on the other side; no contents in the inguinal canal. There was a femoral ring, through which a knuckle of intestine (iieum) had been protruded, and in which it was still lying. The ring had been freely divided, and would admit the tip of the forefinger. The contained piece of intestine was dark and congested, with a deep sulcus marked on it at the point corresponding to the ring and to the seat of strangulation. Here, on the inner gide, a small ragged opening existed, through which frcal matter had oozed. The intestine was adherent for fully one-half of its prolapsed portion to the internal surface of the sac on its outer side. Well marked fibro-cellular bands stretched between the two surfaces; these needed dividing by the knife bemen. There was no lymph effused on that part of the ileum which lay in the sac; but on the abdominal surface, and for an adjoining radiating space of nearly two inches of peritoneal lining, there was effusion of firm and coherent lymph, blocking up the abdominal entrance of the ring, and passing downwards into the true pelvis. There was local peritonitis, not very extensive. Some quantity of dirty serous fluid was found in the true pelvic cavity. There had been no hæmorrhage; no escape of fæcal matter into the abdomen. The intestine was pervious through the damaged portion; it was much congested for some distance, and showed dark patches of mottling from distended vessels; and the internal surface was covered with mucous secretion.

Rmmarrs. It is an old and very true axiom in surgery, that no two cases of hernia submitted to operation are in all points parallel ; and the instance now recorded exemplifies more than one of the rarer accompaniments of a strangulated knuckle of intestine. The coexistence of no fewer than four hernial protrusions; the definite strangulation of one only out of that number, with the somewhat unusual co. incidence of extensive adhesion between the sac and its contained intestine; and the characters of the swelling at the opposite femoral ring, where a thickened but empty sac simulated very closely an omental hernia,-are all points of interest to the practical surgeon.

As is far too often the case, the long delay between the appearance of the symptoms and the operation forbad almost the hope of success; and the poor old man sank, with no attempt at rallying.

I have thought the case worthy of the notice of the members now present, from the practical interest which attaches to those cases of operation where post mortem inquiry has cleared up much that was uncertain during life.

SoldIErg' Food. The United Service Gazette warns us not to forget the soldier's food. The result of under-feeding was seen in the Crimea; and the Gavette is disposed to attribute the late Prussian superiority to the " ounce more of flesh-forming
food." The Prussians get six, the Austrians five ounces; our allowance is four.

\section{色eports}

OF

\section{HOSPITAL PRACTICE: IERTROPOLITAT AMD PROVRTOTAT.}

\section{KING'S COLLEGE HOSPITAL.}

TWO CASES OF EXCISION OF THE KNEH-JOINT. -OPERATION FOR HARE-LIP.-LIGATURING OF VASCULAR TUMOURS. -WOOD'S OPERATION FOR VARICOBE VEINS, AND FOR THIF RADICAL CURE OF HERNIA.

Wr had occasion to see last Saturday, at this hospital, two capital illustrations of the conservative tendencies of modern surgery, conservative in the sense of saving and preserving according to the light of recent progress in science, not in that of standing still and adhering to old rules and customs. Excision of the knee-joint was performed on two patients, who would certainly have had to submit to amputation in years gone by. Sir W. Fergusson was the operator in one case, and Mr. Henry Smith in the other. Nothing could be more unpromising, at first sight, than these two cases; and, in fact, as Sir William remarked of his own patient, twentyfive years ago her limb would have been amputated about six inches above the knee, without a moment's hesitation. Even at the present time, he added, many surgeons would have preferred amputation at the knee-joint to excision. Had he decided on amputation at all, he would have adopted that plan instead of the operation higher up, as the femur was, to all appearances, not affected. After weighing all things, however, he had determined on following the course usually adopted at King's College Hospital, namely, on performing excision.

The patient, a young female, who looked sadly reduced, had been ill for five years. She had no visceral disease; at least none had been made out, although strong suspicions of it were raised by her peculiarly sickly aspect and emaciated condition. The right knee was the joint affected; and, in consequence of the retraction of the hamstring muscles, there was angular distortion of the limb. The operation consisted in making a transverse incision across the joint, below the patella, and, after dissecting upwards in one direction, and downwards in the other, in removing with a saw the lower articular end of the femur and the upper of the tibia. There was no erosion of the cartilaginous covering of the femur, but it was evident that the bone was not sound, from the lion-forceps, used for fixing it before sawing, sinking too easily into it. The periosteum also was too easily removed from the bone; and this, Sir William observed, was an unfavourable sign, because there was, in such cases, a risk of necrosis supervening, although this result need not of necessity follow in every instance, as the bone might have vitality enough within itself to live on. The patella was taken away as useless. As the disease was chiefly seated in the upper end of the tibia, a considerable portion of this bone had to be removed; in fact, a second segment had to be cut away after the first, and even then the remaining cavity of a small abscess had to be gouged out. The retraction of the hamstring musclos was so great that, oren after 